\title{
Preface
}

TN THE BUSY life of Joseph Grinnell, time for deliberative thought often appeared to be at a premium. A man who accomplished the things he did might easily have become so absorbed in his daily tasks that the formulation of a philosophy of nature would never have taken place. But there was nothing drab or routine about Grinnell's thoughts; they were of unlimited horizon. His escape from the danger of becoming a scientific and administrative automaton resulted partly from an innate effervescence of ideas together with a sense of obligation to record them. Reading through his voluminous writings, we pick up many gems of interpretation, crystallized rapidly, often in the field, and under the stimulus of the rich perception gained from his own keen senses. He was quick to react, and the significance of events was rapidly evaluated in his mind.

A more unified fabric of thought on the subject of natural history grew from the considered statements which Grinnell prepared for introductory sections of his general works. Through the years some of these were revised frequently and were enriched by new experience. This body of thought forms the line of emphasis in the selected writings contained in this book. The selections may most benefit those persons who had no opportunity to learn directly from the 'teaching of this master naturalist, but they will also provide refreshment of viewpoint to the numerous company of his students.

A promise was made by Joseph Grinnell, as much to himself as to others, that upon retirement he would write a book of general scope which would present his outlook on the aspects of natural history most related to his own research. This was to be his "one book," as he put it. Happily, we have a late record in his own handwriting of an outline for this book. The memorandum, written one day in the field, gives the chapter headings. These of course would in time have been subjected to the careful scrutiny that characterized all his work. To me the topics that he jotted down envision a definite and solid struc-

$$
\text { [vii] }
$$


ture of theory and example into which as a framework I can see him working many of the separate items contained in the collection now before us. The outline is instructive in itself and is presented here verbatim.

CHAPTER

\section{GEOGRAPHY AND EVOLUTION}

1. The concept of distributional limitation; chronological versus spatial conditions.

2. The nature of barriers; examples of different sorts of barriers in mammals and birds.

3. Distributional areas defined: realms, life-zones, faunal areas, associations; the ecologic niche.

4. Bird migration as a phase of geographic distribution.

5. Kinds of isolation; degrees of isolation as influencing results; the significance of geographic variation.

6. "Plasticity" versus "conservatism" in different groups of birds and mammals.

7. The pocket gophers and the song sparrows of California.

8. Reconcilability of geographic concept with that of genetics; species and subspecies in nature defined.

9. "Orthogenesis" from the standpoint of geographic variation.

10. The bearing of the geography and evolution upon human problems.

Through these chapter headings, and through the pages to follow, run certain themes which I may attempt to indicate. Animal life is locked in a continual struggle for existence. Everything that an organism is and does counts in the equation of survival, and its activities can and must be observed and analyzed in their finest detail. Adherence to this dictum made Grinnell staunchly neo-Darwinian in theoretical outlook. He stood for patient, scrupulous recording of facts seen in naturefor the development of honesty and thoroughness in observational technique and interpretation at a period when the vogue of experimentation was in its most rapid ascendancy. There was in his mind a sound conviction that without acute and exhaustive observation of nature the foundation of evolutionary study was lacking. 
The factors which limit the distribution of animals, based on details of their reactions to environment, form a prevailing theme. Such factors are especially well set forth in his own style in the paper entitled "Presence and Absence of Animals." The metes and bounds of animal geography he surveyed with a view to their causes, histories, and correlations. Geographic limitation, and thus isolation, are the foundations of evolution, and in the geographic race which originates under these influences he clearly saw the nascent species-the most critical stage in evolution. He was, as he put it, "intensely interested in the barely discernible subspecies, because it is in the critical formative stage and there is a good chance that ... something of the causes and essential conditions of its differentiation" may be learned.

The power of the environment to shape the characters of races of animals was a sharp reality to him. Among the striking physiographic contrasts found in the state of California, his own particular field laboratory, he was able to point out factors, climatic and biotic, which had modified many groups of vertebrate species. He showed that there are numerous differentiation centers and faunal areas which are potent regions for environmentally guided evolution. In each of these, parallel modifications are taking place in associated but unrelated species. Selection acting to develop protective resemblance was the principle most generally favored by him in explaining parallelisms in coloration.

Apart from the subject of evolution, we find papers which portray the exacting curator and the stimulating field companion. In still others we sense the philosophy of one who found pleasure in watching the behavior of linnets on a lawn and who reflected with misgivings on human standards of attractiveness when the activities of tree surgeons drove birds from the great oak outside the corner window of his office.

It is in some measure presumptuous to select from a man's writings* what one thinks are his best thoughts. From the items that we offer here each reader may properly choose his own set

- For a complete bibliography see The Condor, XLII (1940), 19-34. 
of especially valued ideas. In presenting this collection, it has been my conviction and that of my colleagues, Seth B. Benson, E. Raymond Hall, and Jean M. Linsdale, that no attempt should be made to arrange the papers in any fashion other than chronologically. A chronology takes no liberty with an author's work and does permit easy tracing of the development of viewpoints. In Grinnell's own tradition, we present the original papers verbatim.

Had Joseph Grinnell lived to gather into his book on geography and evolution the fruits of his years of study in field and museum, its preface would have contained some such acknowledgment as appeared in 1937 on the first page of his preface to Fur-bearing Mammals of California. There he paid grateful tribute to Miss Annie M. Alexander, founder of the Museum of Vertebrate Zoölogy, whose financial support and buoyant encouragement made possible the accumulating of facts which formed the background for theories set forth in his writings. A like tribute, though unvoiced, is here.

Alden H. Miller

Berkeley, California,

October 15, 1941 